\title{
The Brexit Effect on the Possibility of the European Union and the Member Countries to Face the Future Challenges
}

\author{
Constantin Anghelache ${ }^{1}$, Mădălina-Gabriela Anghel ${ }^{2}$, \\ Stefan Virgil lacob ${ }^{3}$, Dana Luiza Grigorescu ${ }^{4}$ \\ ${ }^{1}$ Bucharest University of Economic Studies, Artifex"University of Bucharest, Romania, ${ }^{1} E$-mail: actincon@yahoo.com \\ ${ }_{2}^{2}$,Artifex" University of Bucharest, Romania, \\ 2E-mail: madalinagabriela_anghel@yahoo.com, ${ }^{3}$ E-mail: stefaniacob79@yahoo.com \\ ${ }^{4}$ The Bucharest University of Economic Studies, Romania, ${ }^{4}$ E-mail: danaluiza2004@yahoo.com
}

\begin{abstract}
The latest developments show that the United Kingdom will be able to leave the European Union, following the internal agreement given by the House of Commons (British Parliament), it is clear that negotiations will begin on October 31 to conclude the Brexit documents. In this context, with the acceptance of Britain's exit from the European Union, negotiations will begin, which will not be easy at all, regarding the free movement of goods and people in the European Union. Of course, a number of citizens of the other twenty-seven European Member States work, travel or settle in the United Kingdom. At the same time, a large proportion of British citizens are also temporarily settled, traveling under the Free Movement of Persons Directive in other Member States. On the other hand, it is about the free movement of goods in the European Union. The Member States of the European Union will want to conclude an agreement with the United Kingdom on the free movement of goods which, in a sense, is once again being transformed into import-export trade relations. The United Kingdom, for its part, will be interested, according to all the data currently available, to be included in an agreement with a view to the free movement of goods. But they will not be so easy in accepting the free movement of people, starting from the fact that in the UK, citizens of all Member States move freely. In this respect, between the European Union and the United Kingdom, there will be sufficiently consistent and serious negotiations in relation to the correlation of the two European Union directives on the simultaneous movement of goods and services, but also of persons. The United Kingdom is likely to wish to enter into individual agreements with EU Member States on the free movement of persons. On the other hand, Brexit also means an additional difficulty in setting up the UK's annual and multi-annual budget. In this respect, account must be taken, on the one hand, of the significant share of the United Kingdom's contribution to the Community budget and the not at all impressive amounts which the United Kingdom receives from the European Union, especially in the field of the agricultural budget (ACP) find the distribution method according to the budget that will be formed. Some countries that have difficulty accessing EU funds are likely to receive fewer allowances in the coming period. These are just some of the difficulties that may arise in the face of the Member States of the European Union in terms of how stakeholders and actors, in the Member States, can meet the future challenges that will become more and more numerous and sensitive.
\end{abstract}

Key words

Brexit, Free Movement, Goods, People, Budget, Member Countries.

$\begin{array}{lll}\text { Received: } & 10 \text { May } 2020 \text { (C) The Authors } 2020 \\ \text { Revised: } & 18 \text { Jun } 2020 \quad \text { Published by Human Resource Management Academic Research Society (www.hrmars.com) }\end{array}$

Accepted: 20 Jun 2020 This article is published under the Creative Commons Attribution (CC BY 4.0) license. Anyone may Published Online: 22 Jul 2020 reproduce, distribute, translate and create derivative works of this article (for both commercial and non-commercial purposes), subject to full attribution to the original publication and authors. The full terms of this license may be seen at: http://creativecommons.org/licences/by/4.0/legalcode 


\section{Introduction}

Britain's exit from the European Union has finally taken place under seemingly amicable conditions but, to a lesser extent, with precise deadlines for the future co-operation (co-operation) to be established between the United Kingdom on the one hand. The European Union in the middle of the balance and each of the Member States of the European Union.

In this article we have identified and sought to highlight some aspects that will undoubtedly appear, will materialize and probably, it would be desirable to simplify, but in a practical way, they will probably deepen against the background of contradictions which may exist, we can now say, between the two sides, the European Union on the one hand, the United Kingdom of Great Britain and Northern Ireland on the other. It is no surprise that the representatives of the European Union on the day of the United Kingdom's goodbye by leaving the European Union expressed the opinion that we will continue working with the United Kingdom of Great Britain and Northern Ireland, but under similar conditions that we have with the European Union. This is a statement or point of view without any particular coverage of the prospect of cooperation between the UK and the European Union. We specify this because, if this will be the constant point of view of the representatives of the European Union, it is almost natural for the United Kingdom to ask itself one question for what moment did we leave the European Union if we have to submit to the same legislation?

In passing, it has been said over time, and especially in the last five years, that the United Kingdom has often expressed divergent views on the major problems of the European Union. Of course, the five principles on the free movement of persons, goods, the abolition of visas, access to cooperation, etc., have always been invoked by the parties, except that the United Kingdom has always had a slightly different point of view. We emphasize here that in the period of the European Economic Community, many years ago, the United Kingdom also submitted to the population the expression of a position in a referendum on whether or not to maintain the common market.

The exit of Great Britain will mean other aspects that are worth considering and the authors analyze them in detail in this article. First of all, it is a question of the fact that the annual and multiannual Community budget will have to undergo a series of corrections again, starting from the fact that the United Kingdom has made a major contribution to the financing of the European Union through the budget and will mean a lot. Of course, the criteria will not change, but the volume of the budget will be different. In other words, the simple statement of the British Prime Minister, that we will continue to work with the European Union and the Member States, as long as our views are taken into account. This is from the beginning a special point of view that opposes the point of view of the European Union. For clarification, on the one hand the European Union wants to work with the United Kingdom of Great Britain and Northern Ireland on the basis of European Union law and practice, and on the other hand the United Kingdom claims that it will continue as long as they are its interests, to go beyond the scope of the legislative framework governing the activity of the European Union.

\section{Literature review}

The issue of the United Kingdom of Great Britain and Northern Ireland leaving the European Union is an issue that sparked discussions at the time of this intention, and they intensified, diversified, postponed and finally the decision was made the first fracture of the European Union. The exit of the United Kingdom of Great Britain and Northern Ireland from the European Union certainly raises a number of issues, but at the same time it urges a reformulation of the Community's strategy to cover some of the shortcomings that have arisen from this process and to succeed on a somewhat appropriate path. There are opinions that brexit can be at least a stimulus for other countries where the issue of considering membership of the European Union has somehow faltered. At the same time, there are budgetary problems, which must be reconsidered in the context in which the European Union, by reducing the participation of Great Britain, with its advantages or disadvantages, is experiencing a new crisis. The phenomenon has been studied, annotated and not least considered as an important point in reconsidering the unity of the European Union and achieving the challenges that the European Union itself has proposed through its development strategy. Astfel, Anghel et al. (2017a) expressed the view that the influence of international trade on economic growth in the European Union can be easily destabilized by Britain's exit from this community. 
This is also in the context in which the British relations with the United States are a particular one and could have an effect. Anghel et al. (2017b) they addressed a number of issues related to the development of the information society in the European world, in the Member States, in the context in which from time to time there are also some points that determine certain reorientations in the thinking of the European Union. Anghelache \& Anghel (2015), Anghelache \& Anghel (2017a) and Anghelache \& Anghel (2017b) have addressed in a series of papers aspects related to the evolution of the Gross Domestic Product in the European Union in the current conditions and in perspective, the analysis of the way in which the foreign trade is a growth factor in the European countries and of the European Union as a whole. Anghelache et al. (2020) refers to the fact that at all times international trade, international trade, plays and will play an important role in the evolution of each member country, but especially in the evolution of the European Union in this context. Carkovic \& Levine (2005) addresses a number of issues related to foreign direct investment that are drivers of economic growth. Of course, within the European Union we are talking about the possibility of combining Member States' efforts so that foreign direct investment becomes a natural factor. Unfortunately, the effects of the coronavirus crisis change the meaning of this possibility in the context in which each country, although a member of the European Union, will take more care to restructure resources, to allocate them more efficiently so that the effect of the crisis is as small as possible. The same aspect applies Cicak \& Soric (2015) which emphasizes the interrelationship of investment opportunities and the growth of Gross Domestic Product in the European Union in the context in which each state needs to improve its strategy of being able to offer more, both individually and in cooperation with other Member States. De Michelis \& Monfort (2008) refers to the fact that at regional level it should be noted that the Member States of the European Union, being members at different times, may exert a greater or lesser influence, but in any case they will have to combine their efforts for success. lacob, S.V. (2019) examines the use of statistical and econometric methods to analyse the future evolution of economic growth in one state or another, but in the European Union as a whole. Karacaovalia \& Limão (2008) and Pistoresi \& Rinaldi (2012) they also analyze the liberalization of trade, the liberalization of this exchange of goods in the European world in order to be able to cover the effects that brexit has produced. Not least Pistoresi \& Rinaldi (2012) make a sufficiently relevant analysis of the effect of exports and imports on the economy of any country and consequently of the European Union. Clearly, brexit means a rethinking of intra-Community relations in the sense that there will be some reorientation, some reduction in both imports and exports.

\section{Methodology of Research}

The study of the effects of Brexit on the evolution of the European Union in the future is based primarily on the comparative study method, by comparing the level of development of a country with the complex evolution of the European Union.

We also used the statistical indicators that are available because they are calculated according to the same methodology in all Member States of the European Union and going wider globally give expression to the economic and social potential of each country and can also foreshadow the evolutionary perspectives of each. We also used some statistical-econometric methods based on the Eurostat methodology for calculating indicators (Gross Domestic Product, net salary, gross salary, unemployment, inflation, labor productivity, labor efficiency, renewal of funds and fixed assets, increasing resources, use of labor, etc.), these indicators being interpreted in this article as a system of indicators that gives essence and meaning to the study carried out ensuring the possibility of extending the study, by moving from global analysis to a structural analysis in which to highlight also the important elements in the structure of the national economies of the member countries of the European Union. At the same time, as a methodology we used some statistical representations such as data series, evolution indices, dynamic series, territorial series or national and international comparability indicators.

Through the methodology used we aimed to highlight sensitive aspects that have an effect on the economic evolution of a country, but at the same time we also sought to synthesize at some point, statically, the level of evolution of certain fields of activity and the economy in general. The inductive and deductive methods were widely used in the sense that, in order to extract the opinions that would give essence to the study, we also aimed at exploiting the capacity of deduction and induction in the analysis 
and interpretation of socio-economic phenomena. With regard to the European Union, a number of comparative studies on the evolution of the same indicators in all countries have been widely used, in order to highlight the phase of the European Union as a whole, but also the Member States considered.

\section{Data, results and discussions}

Brexit will soon mean some restrictions that will be imposed by the UK on the free movement of people. Of course, during the transition period that was agreed between the two parties, the effect will not be seen immediately, but it will be gradually reintroduced. It does not take much analysis to understand this perspective and here we refer to the fact that Britain has its own problems, with the native population (of British origin), with the population of the former colonies (new commonwealth) that have settled, mixed with the native population and, last but not least, the population of the new commonwealth countries, which enjoy a number of privileges, a number of advantages which nevertheless create problems for the United Kingdom of Great Britain and Northern Ireland in terms of the total population, the population active, employed population, labor force, unemployed, unemployed population and other transitional categories. The UK is likely to take some individual steps to protect its own demographic and even employment situation.

With regard to the free movement of goods, it will become increasingly clear that the United Kingdom will strengthen its relations with a number of countries, but primarily with the United States and Canada. Of course, the UK will not give up trade, now trade and not sale-purchase, with traditional countries, with markets in which the UK has its own interest and will promote its own interests.

The general background of the brexit problem has another connotation. Lately, there has been a lot of discussion about the reaction of the population in some countries, which is slightly reserved, towards the European community. Many countries, amid dissatisfaction with the support they have anticipated (in most cases not objectively granted), are now thinking more readily that a deeper analysis should lead to a clearer conclusion as to whether European sceptically it is not a point of view sometimes worthy of consideration. Against this background, this process could be amplified by directing the thoughts of some Member States towards the idea of possible departures from the European Union. Sceptically, of course, is not so pronounced in the member states of the European Union, but the phenomenon can deepen. We say this thinking about the fact that after 2019, when we registered the UK patent, in 2020 we started shortly after the new year in a pandemic that launched easily and intensified rapidly, causing major problems to all states the world, of the European states, but especially of the member states of the European Union. Undoubtedly, the coronavirus crisis will certainly deepen and will trigger a large-scale financial-economic crisis, with which mankind has not encountered since 1929-1930.

The cyclical evolution of the world's economy will fall into recession, deep and probably much longer. This recession finds the world's population in a process of population growth (especially in the Asian and African states), which will sweeten by 2050 to about ten billion inhabitants of the Earth, while depleting natural and financial resources.

The economic and financial crisis in the world will have a first effect on reducing production in most countries of the world. Trade will be hampered, major projects started, but those to be launched will be delayed and there will be more and more problems with their financing. Undoubtedly a number of states will leave this sphere of participation in major projects and then worldwide the process of globalization will be, if not compromised, at least stopped and rethought, will be a reset of the economic and financial power of the world's states. In this context, returning to the European Union, we find that now that we put the last commas of this article (in May 2020), many Member States of the European Union are not satisfied with the way the community has been involved and managed to support countries that have been most affected. The most affected were and will continue to be the states in the second category of economic and technical-scientific development, which can lead to a large increase in economic potential between the richest and poorest countries.

Against the background of these problems that we have exposed, we make some concrete analyses on some economic aspects, asking ourselves more than at the beginning of launching this topic, the question on how the European Union will manage to initiate major projects, to draw the member states of the Union. In projects to ensure the fastest possible recovery of losses, lags and all other issues that 
resulted from the two blows received by the European Union through brexit (now it can move into the background in terms of effects) and the coronavirus crisis combined with the economic and financial crisis, which will and will unleash and will have an effect difficult to imagine now on the economy of the world's states. It will be difficult, if not increasingly difficult, for states to find their cadence, for the European Union to have the opportunity and the leverage needed to update the strategy to the conditions currently imposed by the gradual entry into the great economic and financial crisis, so the transition should be slower and easier to bear.

We discuss two points of view of some great economist theorists of the world who even in these moments when we finalize this article launched the possibility that this health crisis combined and continued with the economic and financial crisis has an evolution either U-shaped, which means that it would be somewhat more advantageous if this fall did not lead to an evolution for a number of years (some even anticipate nine to ten years) in the form of $L$. This symbolic evolution $L$ presupposes that there will be an abrupt decrease of the economy of all countries and the world economy, which will remain at a level of decline (deep recession) for as long as possible. Many theorists, after studying the correlation and perspective of population evolution and the exploitation to exhaustion of natural resources, have glimpsed a delicate situation of the perspective of human evolution.

In the article, in addition to some tables taken from Eurostat with reference to the European Union, of some comparisons that take place worldwide, but also of the use of precise statistical-econometric models, we made some correlations between the data we had. At the same time, in order to complete the whole picture and give a much more certain possibility of interpreting the results, we used the presentation of data series in the form of tables and graphical representations that are much easier to interpret and appreciate.

In this article, the authors considered it useful to analyse the evolution of GDP recorded in the European Union over the last twelve years. Therefore, in table number 1 were structured the data related to the evolution of this macroeconomic indicator over a period of forty-eight quarters. The data that have been structured in table number 1 allow a spectral analysis of the evolution of the European Union's GDP from 2008-2019, in order to identify the cyclicality, seasonality and trend of this evolution.

Table 1. Quarterly GDP of the EU in the period 2008-2019

\begin{tabular}{|c|c|c|c|c|c|}
\hline $\begin{array}{c}\text { Quarter } \\
\text { year }\end{array}$ & $\begin{array}{c}\text { GDP (billions } \\
\text { euro) }\end{array}$ & $\begin{array}{c}\text { Quarter } \\
\text { year }\end{array}$ & $\begin{array}{c}\text { GDP (billions } \\
\text { euro) }\end{array}$ & $\begin{array}{c}\text { Quarter } \\
\text { year }\end{array}$ & $\begin{array}{c}\text { GDP (billions } \\
\text { euro) }\end{array}$ \\
\hline T1 2008 & $3.434 .051,00$ & T1 2012 & $3.345 .272,00$ & T1 2016 & $3.742 .585,00$ \\
\hline T2 2008 & $3.270 .525,00$ & T2 2012 & $3.361 .998,00$ & T2 2016 & $3.744 .450,00$ \\
\hline T3 2008 & $3.206 .397,00$ & T3 2012 & $3.378 .808,00$ & T3 2016 & $3.745 .200,00$ \\
\hline T4 2008 & $3.171 .127,00$ & T4 2012 & $3.415 .656,00$ & T4 2016 & $3.753 .076,00$ \\
\hline T1 2009 & $3.020 .120,00$ & T1 2013 & $3.386 .839,00$ & T1 2017 & $3.794 .029,00$ \\
\hline T2 2009 & $2.990 .218,00$ & T2 2013 & $3.393 .612,00$ & T2 2017 & $3.797 .813,00$ \\
\hline T3 2009 & $3.050 .023,00$ & T3 2013 & $3.397 .006,00$ & T3 2017 & $3.801 .617,00$ \\
\hline T4 2009 & $3.111 .023,00$ & T4 2013 & $3.437 .636,00$ & T4 2017 & $4.016 .432,00$ \\
\hline T1 2010 & $3.112 .012,00$ & T1 2014 & $3.487 .897,00$ & T1 2018 & $3.844 .677,00$ \\
\hline T2 2010 & $3.235 .464,00$ & T2 2014 & $3.505 .336,00$ & T2 2018 & $3.964 .177,00$ \\
\hline T3 2010 & $3.204 .448,00$ & T3 2014 & $3.516 .232,00$ & T3 2018 & $3.956 .409,00$ \\
\hline T4 2010 & $3.166 .450,00$ & T4 2014 & $3.581 .988,00$ & T4 2018 & 4.143.782,00 \\
\hline T1 2011 & $3.198 .115,00$ & T1 2015 & $3.477 .722,00$ & T1 2019 & $3.979 .849,00$ \\
\hline T2 2011 & $3.227 .264,00$ & T2 2015 & $3.676 .759,00$ & T2 2019 & $4.090 .074,00$ \\
\hline T3 2011 & $3.293 .400,00$ & T3 2015 & $3.798 .364,00$ & T3 2019 & $4.086 .619,00$ \\
\hline T4 2011 & $3.275 .834,00$ & T4 2015 & $3.901 .262,00$ & T4 2019 & $4.290 .116,00$ \\
\hline
\end{tabular}

Source: Eurostat (data processed by authors) 
In order to highlight the evolution of the indicator analyzed during the forty-eight quarters, the following graph was drawn up (Figure 1).

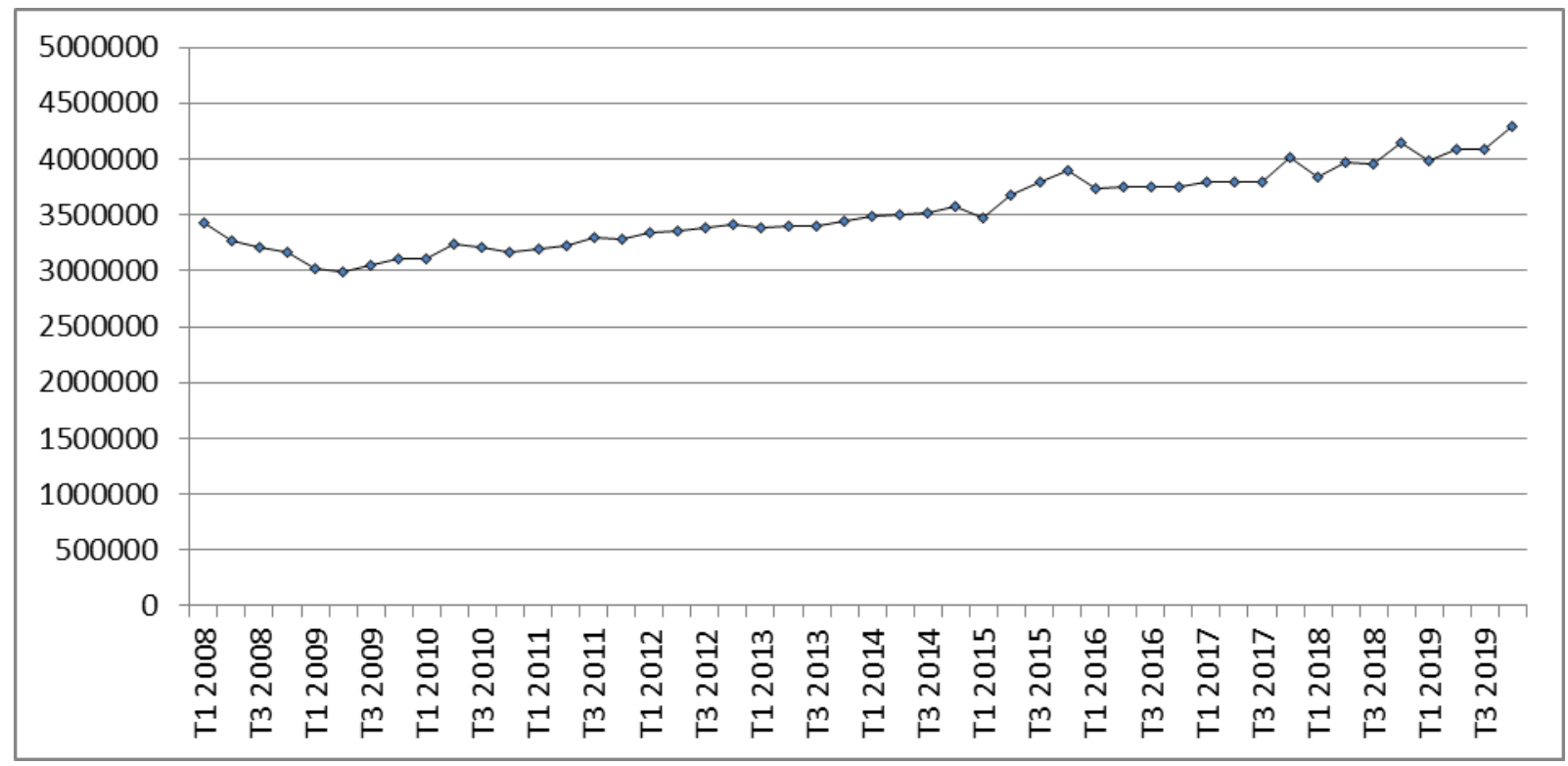

Figure 1. Evolution of EU GDP over the period 2008-2019

Interpreting the data structured in Table 1 and presented in Figure 1 we find that the evolution of this indicator is upward, the maximum being recorded in the fourth quarter of 2019. We also find that the evolution of GDP shows some fluctuations and also analysing a series of sufficiently consistent data, the authors decided to deepen the study using a Fourier series as a basis and to transform the chronological numerical string of data into a finite form of sine and cosine functions, according to the relation:

$y_{t}=\frac{a_{0}}{2}+\sum_{f=1}^{p}\left(a_{f} \cos \frac{2 \pi}{T} f t+b_{f} \sin \frac{2 \pi}{T} f t\right)+u_{t}$

Where: $a_{0}, a_{f}, b_{f}$ represents the parameters;

$T$ represents the number of time units;

$f$ represents the initially set frequency;

$t$ has values in the range $[1, T]$.

The statistical-econometric analysis of the studied phenomenon involves the determination of the estimated parameters $\hat{a}_{\mathrm{f},} \hat{b}_{\mathrm{f}}$, using in this sense the least squares method, a method that involves minimizing the function which in turn involves equalizing with zero the first-order partial derivatives, thus determining the calculation relations of the parameters estimated according to the relations:

$$
\begin{aligned}
& \hat{a}_{f}=\frac{2}{T} \sum_{t=1}^{T} y_{t} \cos \frac{2 \pi}{T} f t \\
& \hat{b}_{f}=\frac{2}{T} \sum_{t=1}^{T} y_{t} \sin \frac{2 \pi}{T} f t \\
& \hat{a}_{0}=\frac{2 y_{t}}{T}
\end{aligned}
$$

After determining the estimated parameters, the amplitude and spectral density can be determined according to the relationships:

$$
\begin{aligned}
& A_{f}=\sqrt{\hat{a}_{f}^{2}+\hat{b}_{f}^{2}} \\
& d_{(f)}=\frac{\hat{p}_{f}}{\hat{\sigma}_{f}}=2\left[1+2 \sum_{k=1}^{\infty} r_{k} \cos 2 \pi \cdot f k\right] \\
& \text { Where: } \quad 0 \leq f \leq \frac{1}{2} \text {, and }{ }^{r_{k}} \text { represents the autocorrelation coefficient. }
\end{aligned}
$$


Using in this study the STATISTICS analysis program, the results in terms of oscillation frequency, Euler-Fourier coefficients, periodogram values and spectral density are structured in Table 2.

Table 2. Data resulting from spectral analysis (Spectral analysis: VAR1 No. of cases: 48)

\begin{tabular}{|c|c|c|c|c|c|c|}
\hline & Frequency & Period & Cosine - Coeffs & Sine - Coeffs & Periodogram & Density \\
\hline 0 & 0,000000 & & $-0,0$ & 0,0 & $1,270549 E-21$ & $7,115953 E+10$ \\
\hline 1 & 0,020833 & 48,00000 & 69352,3 & $-32798,7$ & $1,412517 E+11$ & $8,272158 E+10$ \\
\hline 2 & 0,041667 & 24,00000 & 42221,9 & 20,5 & $4,278450 E+10$ & $8,239397 E+10$ \\
\hline 3 & 0,062500 & 16,00000 & 69466,4 & $-13989,6$ & $1,205110 E+11$ & $7,269294 E+10$ \\
\hline 4 & 0,083333 & 12,00000 & 14500,9 & $-3417,1$ & $5,326904 \mathrm{E}+09$ & $5,024889 \mathrm{E}+10$ \\
\hline 5 & 0,104167 & 9,60000 & 44449,7 & 25489,2 & $6,301127 E+10$ & $4,818608 \mathrm{E}+10$ \\
\hline 6 & 0,125000 & 8,00000 & 48207,8 & 11267,9 & $5,882295 E+10$ & $4,467217 \mathrm{E}+10$ \\
\hline 7 & 0,145833 & 6,85714 & $-1344,1$ & 18261,4 & $8,046814 \mathrm{E}+09$ & $2,753401 E+10$ \\
\hline 8 & 0,166667 & 6,00000 & 23454,4 & 26896,7 & $3,056503 E+10$ & $1,886124 E+10$ \\
\hline 9 & 0,187500 & 5,33333 & 8003,9 & $-10102,4$ & $3,986920 E+09$ & $1,160765 E+10$ \\
\hline 10 & 0,208333 & 4,80000 & 12873,8 & 9182,4 & $6,001194 E+09$ & $9,947348 E+09$ \\
\hline 11 & 0,229167 & 4,36364 & 28481,5 & $-5916,6$ & $2,030884 E+10$ & $1,282652 E+10$ \\
\hline 12 & 0,250000 & 4,00000 & $-2654,7$ & $-19127,0$ & $8,949389 E+09$ & $9,363932 E+09$ \\
\hline 13 & 0,270833 & 3,69231 & $-2832,0$ & $-2785,2$ & $3,786565 E+08$ & $4,320495 E+09$ \\
\hline 14 & 0,291667 & 3,42857 & 7751,1 & $-11617,2$ & $4,680911 E+09$ & $3,963018 E+09$ \\
\hline 15 & 0,312500 & 3,20000 & 9719,7 & 8316,5 & $3,927299 E+09$ & $6,503470 E+09$ \\
\hline 16 & 0,333333 & 3,00000 & 23657,4 & 6475,7 & $1,443853 E+10$ & $8,458003 E+09$ \\
\hline 17 & 0,354167 & 2,82353 & 11623,1 & $-3701,0$ & $3,571032 E+09$ & $5,481930 E+09$ \\
\hline 18 & 0,375000 & 2,66667 & 6580,8 & 592,2 & $1,047775 E+09$ & $2,390288 \mathrm{E}+09$ \\
\hline 19 & 0,395833 & 2,52632 & $-2904,3$ & 2841,8 & $3,962493 E+08$ & $3,949440 E+09$ \\
\hline 20 & 0,416667 & 2,40000 & 22920,1 & 468,1 & $1,261318 E+10$ & $8,162562 E+09$ \\
\hline 21 & 0,437500 & 2,28571 & 16970,7 & $-11061,5$ & $9,848699 E+09$ & $7,985736 E+09$ \\
\hline 22 & 0,458333 & 2,18182 & 1726,4 & $-5058,9$ & $6,857372 E+08$ & $6,385059 E+09$ \\
\hline 23 & 0,479167 & 2,08696 & $-4088,5$ & $-20337,5$ & $1,032790 E+10$ & $1,065664 \mathrm{E}+10$ \\
\hline 24 & 0,500000 & 2,00000 & $-29864,1$ & 0,0 & $2,140473 E+10$ & $1,458419 E+10$ \\
\hline
\end{tabular}

The data indicating the most important oscillations given by the large values of the periodogram and the density are concentrated in Table 3. 
Table 3. Uplifting results (Spectral analysis: VAR1 No. of cases: 48 Largest Periodog. values)

\begin{tabular}{|l|l|l|l|l|l|l|l|}
\hline \multicolumn{1}{|c|}{ Frequency } & Period & Cosine - Coeffs & Sine - Coeffs & Periodogram & Density \\
\hline $\mathbf{1}$ & 0,020833 & 48,00000 & 69352,3 & $-32798,7$ & $1,412517 \mathrm{E}+11$ & $8,272158 \mathrm{E}+10$ \\
\hline $\mathbf{3}$ & 0,062500 & 16,00000 & 69466,4 & $-13989,6$ & $1,205110 \mathrm{E}+11$ & $7,269294 \mathrm{E}+10$ \\
\hline $\mathbf{5}$ & 0,104167 & 9,60000 & 44449,7 & 25489,2 & $6,301127 \mathrm{E}+10$ & $4,818608 \mathrm{E}+10$ \\
\hline $\mathbf{6}$ & 0,125000 & 8,00000 & 48207,8 & 11267,9 & $5,882295 \mathrm{E}+10$ & $4,467217 \mathrm{E}+10$ \\
\hline $\mathbf{2}$ & 0,041667 & 24,00000 & 42221,9 & 20,5 & $4,278450 \mathrm{E}+10$ & $8,239397 \mathrm{E}+10$ \\
\hline $\mathbf{8}$ & 0,166667 & 6,00000 & 23454,4 & 26896,7 & $3,056503 \mathrm{E}+10$ & $1,886124 \mathrm{E}+10$ \\
\hline $\mathbf{2 4}$ & 0,500000 & 2,00000 & $-29864,1$ & 0,0 & $2,140473 \mathrm{E}+10$ & $1,458419 \mathrm{E}+10$ \\
\hline $\mathbf{1 1}$ & 0,229167 & 4,36364 & 28481,5 & $-5916,6$ & $2,030884 \mathrm{E}+10$ & $1,282652 \mathrm{E}+10$ \\
\hline $\mathbf{1 6}$ & 0,333333 & 3,00000 & 23657,4 & 6475,7 & $1,443853 \mathrm{E}+10$ & $8,458003 \mathrm{E}+09$ \\
\hline $\mathbf{2 0}$ & 0,416667 & 2,40000 & 22920,1 & 468,1 & $1,261318 \mathrm{E}+10$ & $8,162562 \mathrm{E}+09$ \\
\hline
\end{tabular}

According to the structured data and presented in table number 3, graph number 2 was generated where the values of the periodogram can be identified vertically, and horizontally the base frequency $(1 / 48)=0.02$ with its harmonics up to $(1 / 48) 24=0.50$.

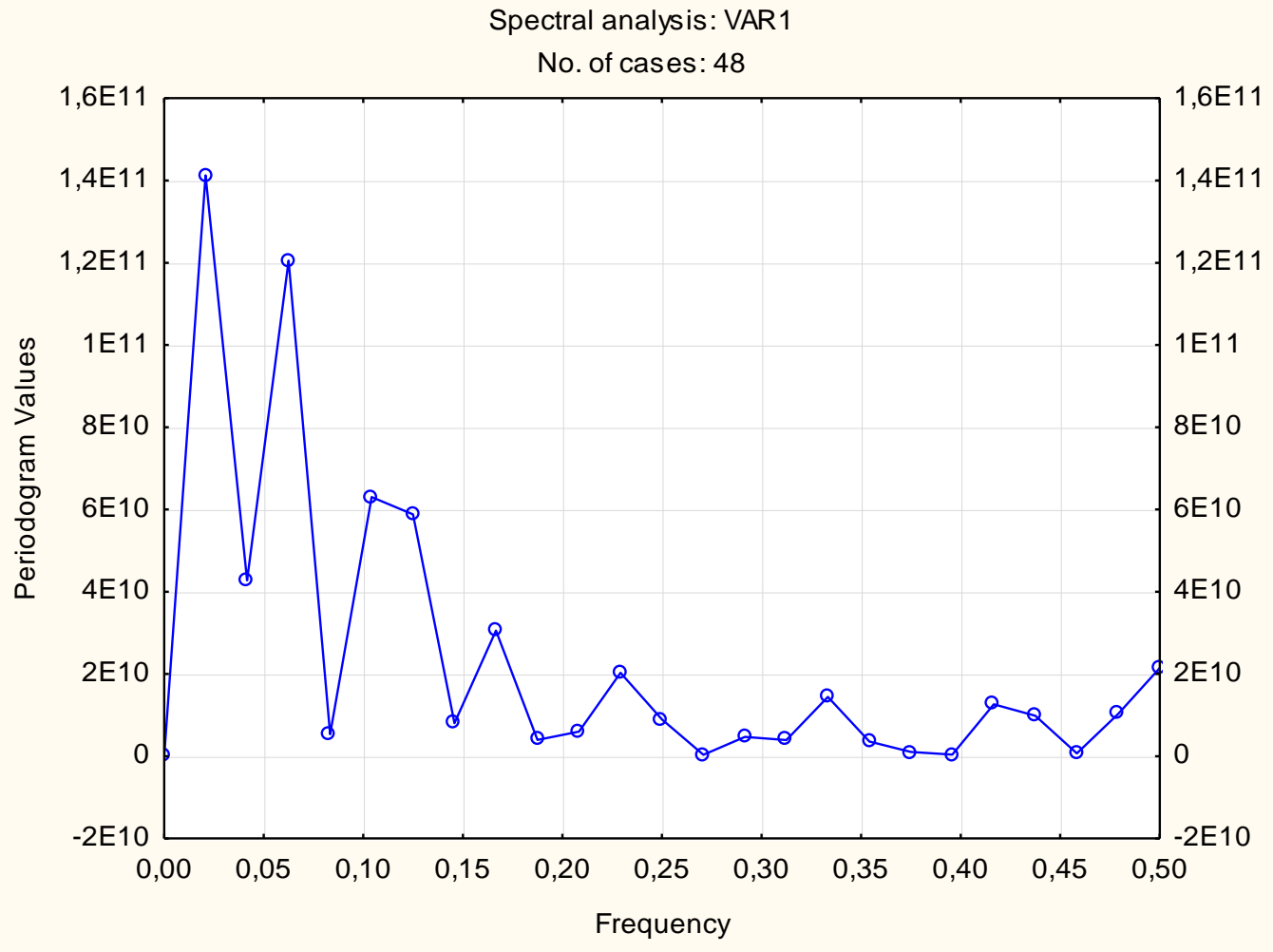

Figure 2. Periodogram values related to frequency

The values of the periodogram relative to the frequency in Figure 2 are determined by summing the squares of the coefficients and then multiplying the result by $T / 2$.

The dependence of the amplitude on the periodogram can be determined according to the relation:

$A=\sqrt{\frac{2-V_{p}}{T}}$

Where: $A$ represents the amplitude

$V_{p}$ represents the value of the periodogram

$T$ represents the number of time units of the series (quarters) 
Interpreting the data structured in table number 3 and represented in graph number 2, we find that the most important oscillations appear at 48 months and 16 months, with the values corresponding to the periodogram of 1.41251 multiplied by ten to the power of eleven and 1 respectively, 20511 multiplied by ten to the power of the eleventh. The following oscillations at 9.6 months and 8 months, respectively, have periodogram values below half of the first two. Thus, finding that the amplitude is high for periods longer than one year (in the case analysed at 48 months and 16 months, respectively) we can say that we can't signal a strong influence of the seasonality of the indicator under analysis. Also, if we follow the evolution of GDP presented in chart number 1 and also if we follow the data series presented in table number 1 , we can see that there are small fluctuations with maximum values in the last quarter of $2017(4,016,432.00$ billion euros), 2018 (4,143,782.00 billion euros) and 2019 (4,290,116.00 billion euros), but they do not characterize the entire evolution of the indicator studied in the period 2008-2019.

High amplitude values (indicated by the periodogram in table number 3 column six), for frequencies lower than the unit value (table number 3 column two), indicate the existence of the trend of the time series of data, which can be confirmed by the slightly ascending evolution of the GDP of the European Union resulting from Figure 1.

In the same vein, we can confirm a cyclicality of revenues recorded in the European Union due to the large amplitudes recorded for periods longer than one year, respectively 48 months and 16 months. In the same vein, this issue will become much more evident after the onset of the economic and financial crisis that will precede the health crisis, coronavirus (COVID 19), which is booming as we complete this article. Also, the evolution of the GDP at the level of the European Union will be influenced in the next period by the result of Brexit, as a result of which Great Britain will no longer directly contribute to the economic growth of the European Union, but indirectly through the bilateral trade results will have them with some member states of the European Union.

Regarding the evolution of the spectral density, it is presented in Figure 3.

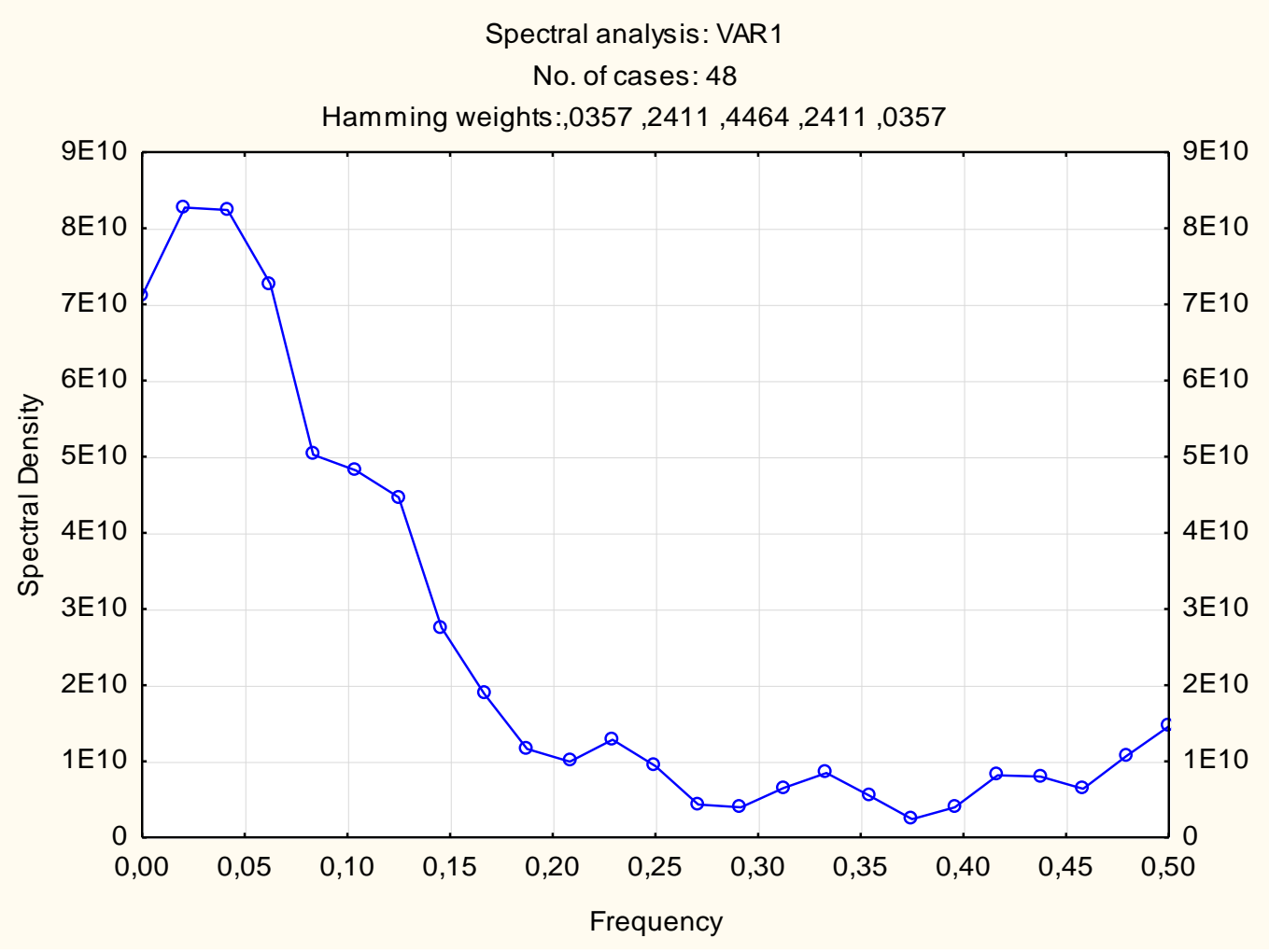

Figure 3. Spectral density relative to frequency

Interpreting the data presented in graph number 3 and table number 3 , we find that in the case of spectral density we have maximum peaks also at 48 months and 16 months, respectively, although the evolution is a bit milder, so to speak. This aspect is somewhat expected given that the values of the spectral density are analogous to those of the periodogram by the calculation expression, which is in fact the first derivative of the process spectrum function. 


\section{Conclusions}

Article written based on the study conducted by the authors, leads to a multitude of theoretical and practical conclusions. First of all, from a theoretical point of view, it is very clear that after brexit, which will have effects that are slightly difficult to anticipate at the moment but really predictable in a few years in the future, there will be effects that will be difficult, if not puts obstacles in the way of promoting the strategies pursued by the European Union. A second conclusion after Brexit is that the United Kingdom will certainly have the two scales in its hands, trying on the one hand to develop relations in the bilateral interest, but especially in its personal interest with the European Union, based on however, negotiations and amicable criteria mutually beneficial to both parties.

Some difficulties may arise with regard to the free movement of persons, with the United Kingdom of Great Britain and Northern Ireland requiring the reintroduction of visas or other self-protection measures. On the other hand, in terms of the movement of goods in the European Union, in Europe now in general, there will be some difficulties in the sense that the United Kingdom will certainly become selective and accept those collaborations, those projects in which it has a major interest.

The problem of investment is becoming for the United Kingdom a prerogative of its own strategies, no longer being in the position of having to respect some conditions of the European Union in their entirety and agree to cooperate with it. It is likely that the United Kingdom of Great Britain and Northern Ireland will become somewhat a competitor of the European Union in the relations that will be developed by the European Union with the United States of America. We are not talking about Canada either, because this state has and will continue to have privileged relations with Great Britain anyway.

In other words, it appears that the Community budget has diminished revenues which will require a new restructuring of the distribution of European Union expenditure by the Member States. We must not forget that the United Kingdom had a contribution of around 10\% of the Community budget.

Brexit will also create some problems within the European Union, according to the authors, in the sense that the United Kingdom will go hand in hand with the development of bilateral relations with a number of community member states, but will do so in the bilateral interest of the United Kingdom and the state considered. Often, if not always the community interest in the same issue that we can mention can be avoided or avoided.

The labor movement will be able to become a problem for the European Union in the sense that this crisis COVID 19 (coronavirus) will greatly reduce the number of jobs, will reduce the investment potential will lead to the reduction of individual incomes of the population as a whole its employees, pensioners or non-employees, with undesirable effects on the outlook on living standards and quality of life.

Another conclusion not necessarily related to brexit, but springing directly from the health crisis and undoubtedly the conjugation of the economic and financial crisis is the reductions of economic activities with an effect on the results of each country. Thus, tourism will be difficult to bring to the level it was in 2019. Major investments will be needed, but other conditions will have to be imposed so that during the pandemic and later this evolution of tourism can be ensured. Tourism, the address called invisible trade, could bring significant income to the population, to some entrepreneurs-investors involved in this field of the tourism industry, but also a possibility to contribute to the formation of the Gross Domestic Product of each country and as a consequence of total global income European Union in Europe and in all the states.

There will be other areas that will have to take a fresh start, such as construction, the area in which the reduction of the population's income will lead to the stagnation of the real estate market with a tinge of moderation and slowdown in investments in this field. Transport has stagnated and needs to be recovered, but the global launch of transport can only be done at the same time as the recovery of tourism and at the same time the recovery of production in industry and other branches of the national economy.

Agriculture will also be an area affected by natural conditions (2020 may be one of the driest in Europe in the last 50 years), which will have effects in the first year 2020, but also with recursions in the next period. Many countries that in terms of food security will have to import more than they do in domestic production. Against this background, in most countries with an evolution to the technological and industrial average, large deficits will appear in the foreign trade balance. 
We conclude in the end that brexit lags behind, but it will continue to have effects within the European Union, but especially the effects of the health and economic and financial crisis will lead to a new reset of the world's states, with different effects for each of the world's states. The Sino-US dispute will probably continue, perhaps combined with Russia, but it is not known if in the not too distant future and with an interference of the European Union in this fight for supremacy, which if it is on a loyal basis should leads to a development, but in many circumstances it can be shown that it can also lead to some rather unfortunate effects for the states of the world, which are in a situation of below average evolution, with difficult prospects to recover. They will increase without right and maybe the debts of the states of the world, which in many countries can reach and even exceed the level of the annual Gross Domestic Product achieved.

\section{References}

1. Anghel, M. G., Anghelache, C., \& Niță, G. (2017). Analysis of the influence international trade on economic growth in the European Union. Romanian Statistical Review, Supplement, 5, 170-184.

2. Anghel, M. G., Anghelache, C., Marinescu, R. T. (2017). The developing the information society in the European Union and the member states. Romanian Statistical Review Supplement, 9, 55-61.

3. Anghelache, C., Anghel M. G. (2015), Model of Analysis of the Dynamics of the DFI (DFI) Sold Correlated with the Evolution of the GDP at European Level, Romanian Statistical Review Supplement, No. 10, pp. 79-85.

4. Anghelache, C., \& Anghel, M. G. (2017). România - membră a Uniunii Europene. Zece ani de la aderare. Bucureşti: Editura Economică.

5. Anghelache, C., \& Anghel, M. G. (2017). International Trade - factor of economic growth for European Union member States, XXIII International Scientific Conference of the PGV Network "The question of borders: a new representation of the European reality", Casablanca, 14-16 September 2017, 267-278.

6. Anghelache, C., lacob, Ș. V., Grigorescu, D. L. (2020), The analysis of the quarterly evolution of the gross domestic product in 2019, Theoretical and Applied Economics, Volume XXVII (2020), No. 1 (622).

7. Carkovic, M., \& Levine, R. (2005), Does foreign direct investment accelerate economic growth. Institute of International Economics Press, Washington DC, 195-221.

8. Cicak, K., \& Soric, P. (2015), The Interrelationship of FDI and GDP in European Transition Countries. International Journal of Management Science and Business Administration, 1 (4), 41-58.

9. De Michelis, N., \& Monfort, P. (2008). Some reflections concerning GDP, regional convergence and European cohesion policy. Regional Science Policy \& Practice, 1 (1), 15-22.

10.Hill, C., \& Smith, M. (2011). International relations and the European Union, Second Edition. Oxford: Oxford University Press.

11.lacob, S. V. (2019). Utilizarea metodelor statistico-econometrice și econofizice în analize economice, Ed. Economică.

12.Karacaovalia, B., \& Limão, N. (2008). The clash of liberalizations: Preferential vs. multilateral trade liberalization in the European Union. Journal of International Economics, 74 (2), 299-327.

13.Pistoresi, B., \& Rinaldi, A. (2012). Exports, imports and growth, Elsevier in its journal Explorations in Economic History, 49 (2), 241-254. 